\title{
RELATO DE CASO: TORÇÃO TESTICULAR EM PACIENTE PEDIÁTRICO
} Pôster

Autores deste trabalho:

Geraldo Gaspar Paes Leme Coutinho : Chefe do Departamento de Pediatria da Faculdade de Medicina Unilago -UNILAGO e Pediatra do Pronto Atendimento Infantil Unimed São José do Rio Preto (SP)

Marina Alves Jacintho de Mello: Acadêmico do Curso de Medicina da Faculdade de Medicina União dos Grandes Lagos - UNILAGO / São José do Rio Preto (SP).

Juliane Eroles Cassillas: Acadêmico do Curso de Medicina da Faculdade de Medicina União dos Grandes Lagos - UNILAGO / São José do Rio Preto (SP).

Luiza Rossoni: Acadêmico do Curso de Medicina da Faculdade de Medicina Uni\&\#257; o dos Grandes Lagos - UNILAGO / São José do Rio Preto (SP).

Marina Magri Magagnini: Acadêmico do Curso de Medicina da Faculdade de Medicina União dos Grandes Lagos - UNILAGO / São José do Rio Preto (SP).

Mariana Morais Olimpio: Acadêmico do Curso de Medicina da Faculdade de Medicina União dos Grandes Lagos - UNILAGO / São José do Rio Preto (SP).

Humberto Brito Caballero: Diretor Médico do Pronto Atendimento Unimed São José do Rio Preto (SP)

João Ferreira da Silva Filho: Enfermeiro do Pronto Atendimento Infantil Unimed São José do Rio Preto (SP)

Área do Trabalho: Pediatria

Data da submissão: $14 / 08 / 2018$ às $22: 49$

\section{Justificativa}

Relatar casos de pediatria.

\section{Objetivo(s)}

Definir através do quadro apresentado pela criança e seguindo os critérios de inclusão e exclusão para o diagnostico de torção de testículo do lado direito encontrados na literatura foi possível confirmar a hipótese diagnostica desse quadro.

\section{Método(s)}

É um estudo descritivo, no qual foi realizada uma pesquisa baseada em um relato de caso ocorrido no pronto atendimento (PA) da UNIMED de São José do Rio Preto.

LILACS, Capes Periódicos, Google Acadêmico.

\section{Resultado(s)}

Paciente A.E, sexo masculino, 12 anos e 6 meses de idade, deu entrada no PA da Unimed referindo dor abdominal intensa a direita e dificuldade para andar. Relata que estava deitado no sofá e sentiu forte dor no abdome, chegando ao PA após 1 hora do início da dor. Apresentava temperatura de $35,7^{\circ} \mathrm{C}$ e peso:48 kg. No começo do exame físico ao ser indagado se doía somente no abdome, o paciente apontou a região genital. Apresentava estado geral regular mas também palidez e dificuldade 


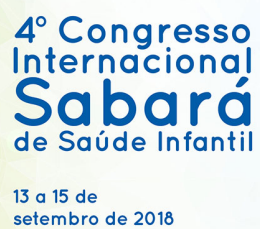

13 a 15 de
setembro de 2018
Hotel Maksoud Plaza
Alameda Campinas, 150
Säo Paulo- Brosil

até para conversar, com dor a palpação do testículo direito e aumento desta dor ao elevar o testículo (sinal de Prehn). A transiluminação foi negativa e foi solicitado ultrassom da bolsa escrotal com urgência. Laudo do ultrassom: testículo direito: dimensões aumentadas, sem fluxo vascular significativo detectável pelo mapeamento de cores Doppler; tamanho: 3,1 x 3,0 x 2,4 cms; volume: $12 \mathrm{~cm} 3$. Testículo esquerdo: fluxo normal; volume: $7,6 \mathrm{~cm} 3$.

Impressão diagnóstica: testículo direito de dimensões aumentadas, com alteração ecotextual e sem sinais de fluxo detectável pelo método, inferindo torção testicular a direita. Presença de pequena hidrocele reativa a direita. Testículo e epidídimo esquerdos normais. O paciente foi enviado para o hospital.

\section{Conclusão (ões)}

Após contato telefônico com o urologista, o paciente foi encaminhado para o hospital após duas horas e meia da torção testicular direita. $\mathrm{O}$ tratamento indicado foi cirúrgico, iniciado preferencialmente nas primeiras 6 horas do ocorrido. 